\title{
Finite Rate Reaction Mechanism Adapted for Modeling Pseudo-Equilibrium Pyrolysis of Cellulose
}

\author{
Tomás Mora Chandía ${ }^{a}$ \\ ${ }^{a}$ Mechanical Engineering Department. La Frontera University(UFRO), Temuco, Chile, tomas.mora@ufrontera.cl
}

\begin{abstract}
:
This works is related to the modeling of cellulose pyrolysis with a pseudo equilibrium approach. The objective is to model the kinetics of the cellulose pyrolysis with a semi-global mechanism obtained from the literature, in order to obtain the yield and the rate of formation of char. The pseudo equilibrium sense consists in the supposition that the solid phase devolatilization can be described kinetically - at finite rate -, preserving the competitive characteristic between the production of char and tar, while the gas phase can be described by means of chemical equilibrium. A set of ordinary, linear and non linear, differential equations was obtained and solved numerically with a simple but consistent scheme using the Totally Implicit Euler method. Chemical equilibrium was solved using CANTERA coupled with a code written in Matlab. Results showed that the scheme preserve the targas competitive characteristic for cellulose pyrolysis. The gas phase, is defined as a mixture of CO2, $\mathrm{CO}, \mathrm{H} 2 \mathrm{O}, \mathrm{CH} 4, \mathrm{H} 2$ and $\mathrm{N} 2$ showed similarly composition compared with models from literature. Finally, the extension of the model to biomass in general, is straightforward, in order to include the hemicellulose and lignin.
\end{abstract}

Keywords: cellulose; pyrolysis; chemical equilibrium; chemical kinetics

\section{Introduction}

Pyrolysis process is a very ancient human activity dedicated mainly to produce charcoal fuel through specifically slow pyrolysis [1]. However, due the increasing shortage, high prices, volatilities and environmental issues, pyrolysis of biomass and waste materials have been considered as a source of chemicals substances and mainly as a carbon-neutral fuel source. This work is devoted to pyrolysis of lignocellulosic biomass, specifically, it proposed a mathematical description of cellulose pyrolysis in a pseudo equilibrium approach. The main objective is to obtain, through chemical kinetics, the rate and yield of char and an approximate prediction of the gas phase composition. The latter is an effort to develop a straightforward tool to assess a pyrolyzer with a procedure that take advantage of the comprehensive empirical and theoretical developments realized so far, about reaction mechanism for biomass in conjunction with chemical equilibrium.

\section{Pyrolysis}

Pyrolysis is one of various process belong to more general group called thermal conversion process, that also include combustion, iron ore reduction, gasification and fine ore sintering among others [2]. If the raw material is biomass it is possible to define the term biomass thermal conversion and then biomass pyrolysis. Di Blasi [3] define pyrolysis like the process in that the mass is heated above $400^{\circ} \mathrm{C}$ and the solid structure starts to decompose into many different products: char, liquids and gases. Authors like, Basu [2] and Bridgwater [4] classify the pyrolysis process as a slow and fast pyrolysis, depending on the heating rate and temperature range, often from 300 to $650^{\circ} \mathrm{C}$. Other author Moldoveanu [5] defines the pyrolysis temperature from above $250^{\circ} \mathrm{C}$ up to $800^{\circ} \mathrm{C}$. Factors like heating rate, particle size, type of biomass, reactor temperature and residence time affect directly the products [1].

Pyrolysis process can be divided in several sub processes: cracking, devolatilization, carbonization, dry distillation, destructive distillation, thermolysis and gas phase cracking [1]. The primary process consist in char, non-condensable and condensable gases production. The latter product can react to 
produce more non condensable gases (carbon dioxide, carbon monoxide, methane, hydrogen, water and others light gases) and lighter condensable gases through homogeneous and heterogeneous reactions.

Slow pyrolysis, named often, carbonization, produce mainly char. The biomass is heated at low rate over an extended period of time in absence of oxygen. The process generate pyrolysis gases or pyrolysates, but due to the extended residence time, the gas phase undergoes further heterogeneous reactions to produce more char [1]. Bridgwater [4] explain that the slow removal of volatiles from the material (mass to reduce) facilitates secondary reactions (heterogeneous reactions) between volatiles and char, which favor the formation of secondary char.

On the other hand, the definition and purpose the of fast pyrolysis, given by Diebold [6], is thermal conversion of biomass to produce mainly condensable organic vapors (also named as liquids or biooils) and minimizing char and gas. Fast pyrolyzers can introduce an amount of air (under stoichiometric) to produce heat to sustain the process. This under stoichiometric combustion produce water vapor and carbon dioxide.

As stated by Basu [1] the primary goal of fast pyrolysis is to maximize the production of liquids. The heating rate is considerably higher than in slow pyrolysis, reaching $10.000^{\circ} \mathrm{C} / \mathrm{min}$. However the maximum temperatures, as mentioned above, is often up to $800^{\circ} \mathrm{C}$. Due to the high heating rates the biomass remains inside reactor less time than in slow pyrolysis.

The composition, size, shape, and physical structure of the biomass exert some influence on the pyrolysis product through their effect on heating rate. Finer particles offer less resistance for condensable gases, which therefore escape relatively fast to the surroundings avoiding the secondary cracking reactions. This results in a higher liquid yield. Larger particles, on the other hand, facilitate secondary cracking reactions due to the higher resistance and has been the older method for charcoal production using stacks with large-size wood pieces [1].

Residence time influences the process as mentioned above. If is necessary to maximize the char, longer residence time is needed for gases in the reaction zone, in order to favor secondary reactions, that can convert liquids in more char. If more gas and volatiles is needed the residence time must be shorter, of the order of milliseconds, and also a fast quenching process after the devolatilization is needed in order to freeze reactions [1].

\section{Mathematical modeling of pyrolysis}

Pyrolysis is very complex multi-stage process from biomass structure and chemical point of view, [1], [3], [4], [7]. Mathematical modeling of fast pyrolysis is very important since they provide knowledge of fuel reactivity, needed for the formulation of reactor designs and scaling rules [3]. The pyrolysis process can be described by two coupled phenomena, kinetics and hydrodynamics. While the former describes the thermal decomposition of materials, the latter describes the transport behavior i.e. mass, energy and momentum. These two phenomena commonly show a strong coupling due to that in order to sustain the thermal decomposition, energy must be supplied. This energy supply can be realized mainly through convection/advection and/or conduction, and in less quantity by radiation [7].

\subsection{Chemical kinetics}

The primary decomposition data of lignocellulosic biomass is often obtained from weight loss analysis, commonly with thermogravimetry, TG, experiments and applying isothermal or dynamic conditions. TG analysis gives the data to construct global or semi global reaction mechanisms [3]. Since the complex structure of lignocellulosic biomass and reaction pathways, independent global or semi-global mechanisms is often used for lignocellulosic components. The devolatilization process from these three components are considered in parallel and independent from each others. The latter is an hypothesis with an a good experimental verification, and it is named the superimposed approach 
[8]. However, all the products released from the components into the gas phase participate in a competitive manner to produce the final products.

The TG analysis can reveal the thermal behavior of a sample of any kind of material susceptible to thermal decomposition. However, if the pure kinetic effect is pursued, Di Blasi [3] and Branca [9] states that heat and mass resistances must be avoided. For example, in pure cellulose pyrolysis, the Levoglucosan i.e. LVG, the main component released, is decomposed inside the particle if there is an imposed a restriction to flow out [10]. This restriction i.e. mass resistances-transport effect, produce more char. Therefore, the transport effect is superimposed and no pure kinetics is obtained. Other related factors mentioned by Di Blasi [3] are the endo-exothermicity and thermal inertia.

Reaction mechanisms can be classified by the level of detail. A one step global mechanism include only one reaction with kinetic constants and describe the evolution of three main products char, liquids and gases. However, as stated by Di Blasi [3] and Arsenau [10] competitive reactions exists in the pyrolysis process, therefore a one stage and parallel reaction mechanism is more suitable, and have the advantage that it is possible to predict the products distribution. More detailed mechanisms include the secondary cracking reactions. Secondary reactions are heterogeneous processes, catalyzed by char, that can break down the primary vapors to produce light liquids, gases and more char [1], [3].

A commonly used reaction mechanism for the thermal decomposition of cellulose is the BroidoShafizadeh [21]. A one stage mechanism with parallel reactions describes the char, liquid and gas yields in a competitive way [11]. The modified Briodo-Shafizadeh mechanism (Fig. 1) has four reaction in series and parallel that include: first degradation that produces activated cellulose; dehydration; depolymerization, producing LVG (a liquid precursor); and secondary cracking reactions. Other examples are the two stage mechanism with secondary reactions given by Diebold [11] and the superimposed reaction mechanism given by Ranzi [12].

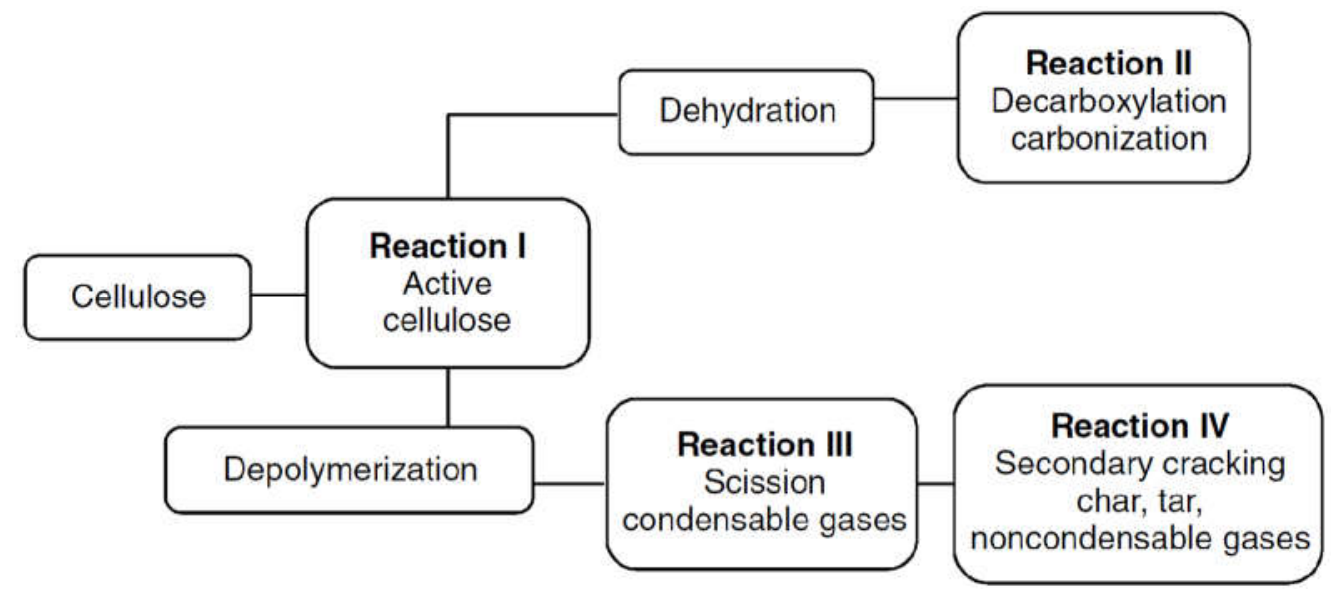

Fig. 1. Broido-Shafizadeh mechanism [1].

\subsection{Equilibrium modeling}

Pyrolysis process, as mentioned above, is a thermal process, therefore it can be described thermodynamically. Since pyrolysis include chemical reactions thermo-chemical process description is needed. Thermodynamics is a powerful discipline that allow to predict thermal processes, essentially, considering a set of equilibrium states. A process in thermodynamics is approximated by an infinite successive steps that allow to reach a final equilibrium state. In actual processes, if the final state is in thermodynamical equilibrium i.e. mechanical, thermal and chemical equilibrium, the solution is exact and can be obtained independently of the path [13]. An important issue is that thermodynamics give information only about initial and final states, but no information can be obtained about the pathway.

Actual thermal systems seldom reach the thermodynamic equilibrium due to their characteristic time scale is finite, while in thermodynamics, the time scale is by definition, infinitely large. An advantage of thermodynamic analysis is that an approximate solution can be obtained with a minimal input 
information. Therefore, for example, if the kinetics is not known, an estimative is always available. Other advantage is that thermodynamics defines the limits of the process, and any non thermodynamical description cannot produce results beyond these limits.

In dealing with chemical systems, the thermodynamic equilibrium can be calculated using the entropy principle. For an adiabatic closed system, entropy can only increase as the system reach the equilibrium. Equivalently the Gibbs free energy reach a minimum in the same process [22]. The later property i.e. Gibbs free energy is often used for equilibrium calculation in chemical systems.

There are two methods to assess chemical equilibrium: the stoichiometric and the non-stoichiometric. The former is based on the thermodynamic equilibrium constants $K_{p}$, and a set of chemical reaction is needed. The equilibrium is obtained by solving a set of linear and non-linear algebraic equations, often numerically, using an iterative solver [14]. As stated by Vonka [15] this is a simple method if the number of species is reduced. The latter method has the advantage that reactions and equilibrium constants are not needed. Gibbs free energy is applied in conjunction with elemental species and chemical potentials. A set of nonlinear equations are obtained, and a minimization process of Gibbs free energy is applied including mass restrictions in order to obtain a solution. The solution procedure is more complex compared with the stoichiometric method, but is more suitable in dealing with systems with a higher number of species [15].

In order to solve the chemical equilibrium some solvers are available and mainly these software packages use the non-stoichiometric approach. The most used solver is CHEMKIN, a commercial package that has been developed mainly for kinetics, but also contains an equilibrium solver. Other commercial package used by researchers is ASPEN plus. Finally, a free distributed package is CANTERA. This free software has been developed by the California Institute of Technology using the python language. CANTERA has solvers for kinetics, fluid dynamics and thermodynamics, useful for reactor modeling, and can be used coupled with codes written in Matlab, C++ or Fortran (See http://www.cantera.org).

Although thermodynamic description of thermal processes has some disadvantages, these principles can be applied on dynamic descriptions. For example, in combustion a partial chemical equilibrium is assumed when an intermediate species is consumed faster after an initially rapid production [14]. In this case this species can be considered in chemical equilibrium and allows the introduction of the kinetic constant $\mathrm{K}_{\mathrm{c}}$. This kinetic constant is a function of the forward and backward kinetic coefficients and is related with thermodynamical equilibrium constant $K_{p}$ [14]. In gasification of biomass an approximate equilibrium description is applied in the reduction zone of a Downdraft gasifier since the products has enough time to reach a nearly equilibrium state [16]. Also in a entrained flow reactor equilibrium approach is often applied due the high process temperatures, above $800^{\circ} \mathrm{C}[17]$.

It can be encountered in the literature pure equilibrium models for pyrolysis, often for gasification. Baratieri [18] used the non-stoichiometric formulation to predict the Syngas composition from different biomass waste materials and temperatures from 500 to $1000^{\circ} \mathrm{C}$. The process was modeled at constant pressure and temperature in presence of water steam and considering partial combustion to sustain the process. An interesting approach is the application of chemical equilibrium between the solid char and pyrolysis gases, a different approach compared with common equilibrium models. The gases considered were $\mathrm{CO}_{2}, \mathrm{CO}, \mathrm{H}_{2} \mathrm{O}, \mathrm{CH}_{4}$ and $\mathrm{H}_{2}$. Other gases were not considered due to the trace concentration showed in pre assessment. Solid-gas phase equilibrium was calculated with the CANTERA package. Results showed that at low temperatures $\mathrm{CO}_{2}$ y $\mathrm{CH}_{4}$ were favored while at higher temperatures the conditions favored $\mathrm{H}_{2}$ and $\mathrm{CO}$ gases. The author also evaluated the influence of equivalent ratio i.e, ER and the steam to carbon ratio i.e. SC. The results showed that an increase in both parameters caused an increase in $\mathrm{N}_{2}$ and $\mathrm{H}_{2} \mathrm{O}$ concentration due to combustion and high water steam content.

Altafini [17] conduct a fixed bed gasifier simulation with an inverted flow considering an equilibrium description. The test material was sawdust of pinus elliotis, with $10 \%$ humidity, dry basis. Simulation with partial combustion was conducted at $800^{\circ} \mathrm{C}$ and 0.93 bar i.e. local atmosphere pressure. The 
influence of humidity was evaluated from 0 to $30 \%$, dry basis. Chemical species belonging to the gas phase were: $\mathrm{CO}_{2}, \mathrm{CO}, \mathrm{H}_{2} \mathrm{O}, \mathrm{CH}_{4} \mathrm{y} \mathrm{H}_{2}, \mathrm{y} \mathrm{N}$. The equivalence ratio $\mathrm{ER}$, was adjusted to obtain $800^{\circ} \mathrm{C}$ in all the simulations. The system of equation obtained was solved using the SYNGAS routine for FORTRAN and Newton-Raphson iterative method. Qualitatively, results showed that as the humidity increase the process temperature decreases being necessary more air for combustion to maintain a $800^{\circ} \mathrm{C}$ temperature. Another effect of humidity was the lower content of $\mathrm{H}_{2}$ and $\mathrm{CO}, 1.6 \%$ y $8.92 \%$ respectively, and also, a higher content of $\mathrm{CO}_{2}$ with $5.32 \%$, while methane content was negligible.

In an effort to obtain more suitable results using the chemical equilibrium for the thermal decomposition of biomass, some author has been explored models combining the equilibrium and the dynamical approaches. This hybrid approach requires additional parameters apart from the thermodynamic properties, such as the elemental composition of biomass.

Gobel [19] develop a model of a multi-stage fixed bed gasifier in order to assess the reactor performance and with the objective to obtain a control strategy. The work has consisted in the development of an one dimensional model considering the continuity and energy equations for gases, defined in chemical equilibrium. Gas phase composition was defined with $\mathrm{CO}_{2}, \mathrm{CO}, \mathrm{H}_{2} \mathrm{O}, \mathrm{H}_{2}, \mathrm{CH}_{4}$ and $\mathrm{N}_{2}$, in which the two latest were considered such as inactive gases. The Reactor geometry was defined as a cylinder and the hydrodynamic regime was approximated with the plug flow reactor approach, i.e. without radial distribution of variables [14]; with negligible pressure drop; without intraparticle transport; without TAR presence, and finally, char was considered as pure carbon i.e. graphite. The kinetic factor was introduced by an evolution equation for char reactivity as a function of temperature and biomass properties. Various Arrhenius parameters for kinetics were obtained experimentally from TG analysis. A particle structure description was applied considering two models: the shrinkage and porous model. Time rate equation i.e. kinetics, was solved using the simulation language SIL, while mass and energy equations was solved with the finite volume method. Simulations results was compared with data obtained from an experimental plant of $100 \mathrm{~kW}$. Results showed an overestimated prediction of temperature inside the reactor, although, the estimated exit temperature match the experimental data. Also, the shrinkage model showed the best results, with a good bed height estimation. Finally, the model predict a slightly, but significantly, lower heating value compared with the experimental data.

Other combined model was developed by Lee [16]. This model has the characteristic that the author could combine two existence software packages to achieve a simulation of pyrolysis. The author used in a consecutive way the HSC package, a software to calculate chemical equilibrium and the Sandia PSR i.e. a Perfect Stirred Reactor code for kinetics calculations (coupled with CHEMKIN), designed for combustion. The material used was waste biomass from the palm oil production. The approach consisted in to obtain an equilibrium composition (with HSC) starting from the elemental analysis of biomass material, and then, use this composition as an input in the PSR code. Since the PSR code is designed for combustion, a special setup was applied. The HSC code produced the expected composition for chemical equilibrium i.e. mainly $\mathrm{CO}_{2} \mathrm{CO}, \mathrm{H}_{2} \mathrm{O}, \mathrm{CH}_{4}, \mathrm{H}_{2}$, and $\mathrm{N}_{2}$. However PSR code could predict a significant amounts of species such as $\mathrm{C}_{2} \mathrm{H}_{2}, \mathrm{C}_{2} \mathrm{H}_{4}, \mathrm{C}_{2} \mathrm{H}_{6}$ o el $\mathrm{C}_{3} \mathrm{H}_{8}$, species observed only in kinetics models.

\section{Pseudo-equilibrium mathematical description}

The objective of this work is to develop a reduced model for the devolatilization of cellulose considering the gas phase in chemical equilibrium. The present work must be a part of a more general model for a fixed bed reactor needed to predict the yield and rate of formation of char for their use in the eco-fertilizer industry. In this application liquid and gas substances are considered by-products, and the main goal is to achieve the maximum char as possible. Therefore, is required a compact model, for engineering purposes, to predict the thermal behavior of the reactor and the char yield, in order to assess different designs, scale ups, optimization and control. 
From the mathematical modeling point of view the main factor is the formation rate and the final yield of char. Details of the composition of liquid and gas substances has a minor importance at this initial stage. Therefore in order to obtain a more suitable char evolution description, the kinetics must be applied. The whole gas phase, i.e. gases and liquids, are also important due to there are homogeneous chemical reactions that can consume or release energy affecting the reactor temperatur. Therefore the whole gas phase is an important energy carrier inside the reactor. In this work it is proposed that the detail composition of the gas phase do not affect considerably the char formation and is good starting point to obtain a model for engineering purposes.

The first step in order to develop the reactor model is the definition of the chemical framework. This work only describe the development for cellulose. However, since it is possible to apply the superimposed approach [8], the inclusion of hemicellulose and lignin components will be treated as an extension.

\subsection{Process description}

A whole reactor model can include a field description of the conservation of mass, energy and momentum. However, in the current work only issues relative to the mass conservation is needed. An idealized reactor is described in Fig. 2. The process is considered at constant pressure. Temperature can be constant or variable in time i.e. applying a heating rate. Geometry and transport characteristics are not included. Also, gradients of temperature, concentration and pressure are not considered.

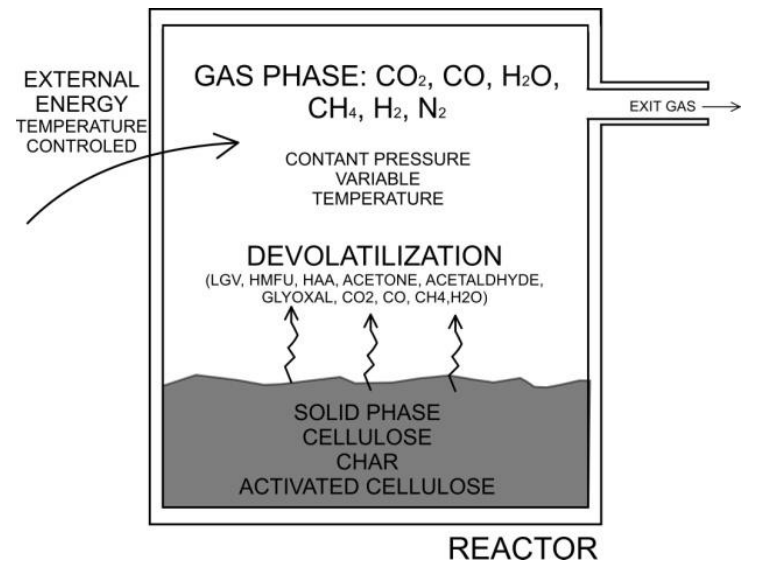

Fig, 2. Idealized reactor.

As can be seen in Fig. 2, the heat added to the reactor warm up the solid and the gas phases and induce the exit of mass. As the devolatilization is taking place, the density of the solid decrease and gradually the biomass is converted to char. Since the pressure is considered constant, an amount of the chemical species released from the solid phase, must be removed from the reactor.

Under this simple reactor description, a reaction mechanism (kinetic model) is needed in order to describe the yield and formation rate of char. For this purpose a two stage parallel and semi-global mechanism for cellulose given by Ranzi [12] was chosen.

\subsection{Reaction mechanism for cellulose}

The cellulose mechanism developed by Ranzi [12] is showed in Fig. 3. This mechanism belongs of a more complete scheme that include reactions and kinetic data for hemicellulose and lignin. This scheme has been used by Miller [8] with additional reactions to describe the secondary cracking in order to develop a more comprehensive pyrolysis model, including hydrodynamics. 


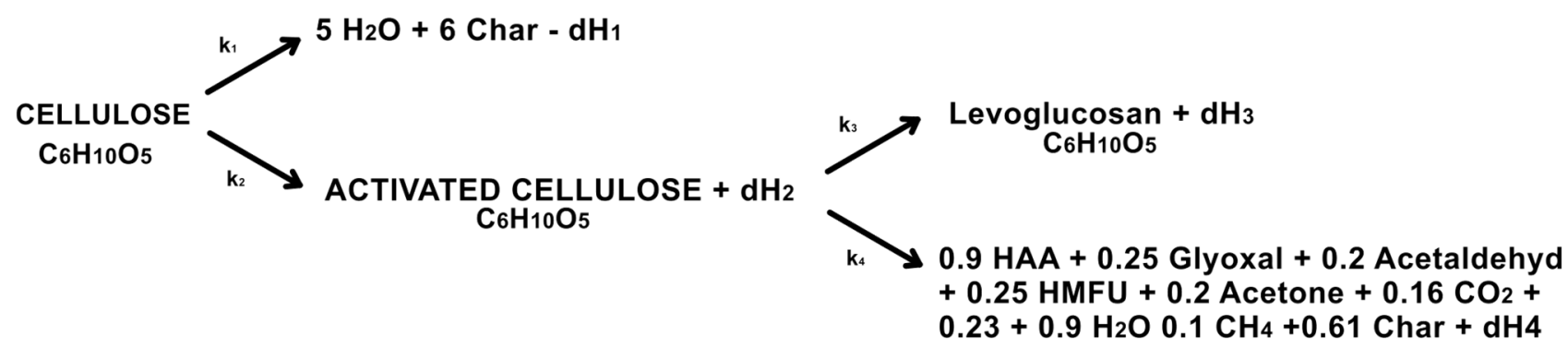

Fig. 3. Two stage parallel semi-global mechanism by Ranzi [12].

As can be observe in the Fig. 3, cellulose is decomposed irreversibly and in a competitive way in: activated cellulose i.e. with the same elemental composition of cellulose but with different stereo configuration and properties [12]; and on the other hand, in water steam and char. Both reactions has its own kinetic constants shown in table 1. In a consecutive manner, activated cellulose is decomposed irreversibly in LVG, and in a set of gaseous specie.

As stated by Arseneau [10] LVG can be released as a gas or can participate in intra-particle reactions catalyzed by char to produce different non-condensable gases.

In table 1 shows the details of the reactions and their kinetic parameters. It can be observed the higher activation energy value for (R1), that produces activated cellulose and gases. Also it can be observed that the activation energy for (R2) is significantly lower, therefore, for lower temperature the char yield is favored. This is an advantage of the parallel semi-global mechanism, the competitive factor.

\subsection{Mechanism adaptation}

In order to consider the gas phase in chemical equilibrium, thermodynamic data is needed for all species. The software package CANTERA, used in this work, contains a large set of thermo-chemical data for common species. However species like HAA, Glyoxal, Acethaldehyd, HMFU is not present in the data base. One solution is to obtain all the data needed for either, Shomate or NASA polynomials in order to obtain the thermodynamics properties. However, since that the equilibrium solver of CANTERA is based on the non-stoichiometric method, the gas phase equilibrium can be solved directly with the elemental composition. Therefore, for this purpose the elemental composition of the gas phase must known (with any other two thermodynamical variables) over the whole simulation. As can be observed in Fig. 3, species from the solid phase are released as the devolatilization take place, therefore, the elemental composition change constantly In the next section a procedure is proposed to account this change based on the species conservation equations.

This model is a multiphase scheme, since there are two phases. Both phases are defined by a volumetric fraction, because no hypothesis are made about the shape of the biomass particles. Solid phase is comprised by an a mixture of cellulose, activated cellulose and char, each characterized by its density, although the total solid volume fraction, also the gas volume fraction, is considered constant.

The species LVG, HAA, Glyoxal, Acetaldehyde, HMFU, Acetone, H2O and the others gases in (R1)(R4) are considered released in gas state from the solid phase, however these substances are not defined in the gas phase (as can be seen in Fig. 2). While char product from (R2) and (R4) is considered belong only to the solid phase. The approach used here consists in to convert the total substances released from the solid phase into an equivalent system composed solely of elemental carbon $\mathrm{C}$, elemental hydrogen $\mathrm{H}$ and elemental oxygen $\mathrm{O}$, in order to calculate the chemical equilibrium. The amount of gas released from the solid phase will have the same elemental composition and the same total enthalpy, however different temperature and pressure. This approach do not affect the final chemical equilibrium due to the unique characteristic solution of the equation system. 
Table 1. Kinetic parameters for the reaction mechanism [12].

\begin{tabular}{|c|c|c|c|c|c|}
\hline $\begin{array}{c}\text { Reactio } \\
\mathbf{n}\end{array}$ & Reactant & & Products & $A[1 / s]$ & $\begin{array}{c}\mathbf{E} \\
{[\mathrm{kJ} / \mathrm{mol}} \\
]\end{array}$ \\
\hline R1 & Cellulose & $\begin{array}{l}== \\
>\end{array}$ & Activated Cellulose & $8 \mathrm{E}+13$ & 192,5 \\
\hline $\mathbf{R 2}$ & Cellulose & $\begin{array}{l}== \\
>\end{array}$ & $5 \mathrm{H}_{2} \mathrm{O}+6$ Char & $8 \mathrm{E}+07$ & 125,5 \\
\hline R3 & $\begin{array}{l}\text { Activated } \\
\text { Cellulose }\end{array}$ & $\begin{array}{l}== \\
>\end{array}$ & LVG & $4 * \mathrm{~T}$ & 41,8 \\
\hline R4 & $\begin{array}{l}\text { Activated } \\
\text { Cellulose }\end{array}$ & $\begin{array}{l}== \\
>\end{array}$ & $\begin{array}{l}0,95 \mathrm{HAA}+0,25 \text { Glyoxal }+0,2 \\
\text { Acetaldehyde }+0,25 \mathrm{HMFU}+0,2 \\
\text { Acetone }+0,16 \mathrm{CO}_{2}+0,23 \mathrm{CO}+0,9 \\
\mathrm{H}_{2} \mathrm{O}+0,1 \mathrm{CH}_{4}+0,61 \mathrm{Char}\end{array}$ & $1 \mathrm{E}+09$ & 133,9 \\
\hline
\end{tabular}

As a consequence of the approach the species LVG, HAA, Glyoxal, Acetaldehyde, HMFU and Acetone do not belong to any phase. This process it can be described as follows. Species LVG, HAA, Glyoxal, Acetaldehyde, HMFU and Acetone are produced in the solid-gas interface and react infinitely fast to produce the species defined in the gas phase, in other words, these species only exists in the interface and have an infinitely short life time. Also, the elemental composition do not belong to any phase, and is only a chemi-mathematical manipulation to obtain the chemical equilibrium.

\subsection{Devolatilization model}

Since the zero dimensional characteristic of the model (do not account field effects), the velocity field, and then, momentum conservation equation are not needed. Also energy conservation equation is possible to be used to know the energy requirements to sustain the process, however this will be studied later in other article. Therefore, the only equation needed is the mass conservation, one for each phase.

\subsubsection{Mass conservation equation for solid phase}

Two volumetric phases are defined in which an integral average of properties is applied, corresponding to an a Euler-Euler approach [23]. Since in this approach a surface is not defined, is not possible to apply a flux term between the phases in the conservation equations. Therefore the mass exchange is made trough a source term. The mass conservation equation for the solid can be defined as:

$$
\frac{\partial \rho_{s}}{\partial t}=\dot{S}_{\text {devo }}
$$

Where $\rho_{s}$ is the total solid phase density and $\dot{S}_{\text {devo }}$ is the rate of devolatilization. $\dot{S}_{\text {devo }}$ can be calculated from the species conservation equation [14]

$$
\frac{\partial \rho_{s} Y_{i}}{\partial t}=\dot{S}_{\text {devo,i }}
$$

Since [14]

$$
\sum \frac{\partial \rho_{s} Y_{i}}{\partial t}=\sum \frac{d \rho_{i}}{d t}=\frac{\partial \rho_{s}}{\partial t}
$$

Then 


$$
\sum \dot{S}_{\text {devo,i }}=\dot{S}_{\text {devo }}
$$

Considering the following irreversible reaction

$$
A==>v_{B} B+v_{C} C
$$

a rate equation is defined for $\mathrm{B}[20]$ as:

$$
\frac{d[B]}{d t}=-v_{B} \frac{d[A]}{d t}
$$

in molar basis. Since Ranzi [12] specified that the rate of reaction is defined by a first order Ahrrenius type, the second term in (6) can be expressed as:

$$
\frac{d[A]}{d t}=-k[A]
$$

in molar basis too. Letter $k$ is the kinetic constant defined by the modified Arrhenius equation

$$
k(t)=A_{0} T^{n} \exp (-E / R T)
$$

where $A_{0}$ is the pre-exponential factor and $E$ is the activation energy. The superscript $\mathrm{n}$ is the temperature factor introduced to improve the ordinary Arrhenius equation. The concentration $[A]$ in (7) can be the cellulose, or activated cellulose according to the reaction mechanism (Table 1).

Equations (6) and (7) can be expressed in mass basis multiplying them by its molar mass:

$$
\begin{gathered}
M_{B} \frac{d[B]}{d t}=\frac{d \rho_{B}}{d t}=-v_{B} M_{B} \frac{d[A]}{d t} \\
M_{A} \frac{d[A]}{d t}=\frac{d \rho_{A}}{d t}=-k M_{A}[A]=-k \rho_{A}
\end{gathered}
$$

Therefore all the products in the mechanism can expressed combining (9) and (10):

$$
\frac{d \rho_{B}}{d t}=-v_{B} \frac{M_{B}}{M_{A}} \frac{d \rho_{A}}{d t}
$$

Since some species can be produced in more than one reaction a more general expression is given by:

$$
\frac{d \rho_{B}}{d t}=-\sum_{i=1}^{M} \quad v_{B, i} \frac{M_{B}}{M_{i}} \frac{d \rho_{i}}{d t}
$$

The solid phase in defined by the Cellulose, activated cellulose and char, therefore by definition (3) can be expressed as a sum of each components

$$
\frac{\partial \rho_{\text {Cell }}}{\partial t}+\frac{\partial \rho_{\text {ACell }}}{\partial t}+\frac{\partial \rho_{\text {Char }}}{\partial t}=\dot{S}_{\text {devo }}
$$

Equation 13 can be solved using (7) applied for cellulose and activated cellulose and with (12) for char. All the others quantities computed from equation (12) are the total mass released in the gas phase.

Applying (10) for cellulose and (12) for activated cellulose gives:

$$
\begin{gathered}
\frac{d \rho_{\text {Cell }}}{d t}=-\left(k_{1}+k_{2}\right) \rho_{\text {Cell }} \\
\frac{d \rho_{\text {ACell }}}{d t}=k_{1} \rho_{\text {Cell }}-\left(k_{3}+k_{4}\right) \rho_{\text {Cell }}
\end{gathered}
$$


Molar mass ratio disappear on the first term in the right hand because molar mass of cellulose and activated cellulose are equal. Completing the rates for solid phase, char equation is obtained from (12).

$$
\frac{d \rho_{\text {Char }}}{d t}=6 k_{2} \rho_{\text {Cell }}+0,61 k_{4} \rho_{\text {ACell }}
$$

All the other rates are obtained applying (12), and kinetics constants $k$ are obtained using (8) and data from Table 1. A very useful (for computational calculation) way to obtain the yields of gaseous species is applying the form given by Turns [14]

$$
\begin{gathered}
\dot{\omega}_{j}=\sum v_{j i} q_{i} \\
v_{j i}=\left(v_{j i}^{\prime \prime}-v_{j i}^{\prime}\right) \\
q_{i}=k_{f i} \prod \quad\left[X_{j}\right]^{v_{j i}^{\prime}-k_{b i} \prod}\left[X_{j}\right]^{v_{j i}^{\prime \prime}}
\end{gathered}
$$

Where $v_{j i}^{\prime}$ and $v_{j i}^{\prime \prime}$ are $M \mathrm{x} N$ are matrices (see Table 2 and Table 3 ), where $M$ is the number of reactions and $N$ the number of species in the mechanism. The $v_{j i}^{\prime}$ is the matrix that contains the stoichiometric coefficients for reactants and $v_{j i}^{\prime \prime}$ include the stoichiometric coefficients of products while $\left[X_{j}\right]$ are the instantaneous molar fraction. This expression can be expressed in a mass basis by multiplying them by the respective the molar mass. Equations (12) and (17)-(19) produce the same set of equation than equations.

A system of ordinary nonlinear differential equations are obtained and must be solved simultaneously.

Table 2. Reactants $v_{j i}^{\prime}$ matrix for (18).

\begin{tabular}{cccccccccccccc}
\hline Reaction & Cell & ACell & Char & LVG & HAA & Glyoxal & Acetaldehyde & HMFU & Acetone & $\mathbf{C O}_{2}$ & $\mathbf{C O}_{2}$ & $\mathbf{H}_{2} \mathrm{O}$ & $\mathbf{C H}_{4}$ \\
\hline 1 & 1 & 0 & 0 & 0 & 0 & 0 & 0 & 0 & 0 & 0 & 0 & 0 & 0 \\
2 & 1 & 0 & 0 & 0 & 0 & 0 & 0 & 0 & 0 & 0 & 0 & 0 & 0 \\
3 & 0 & 1 & 0 & 0 & 0 & 0 & 0 & 0 & 0 & 0 & 0 & 0 & 0 \\
4 & 0 & 1 & 0 & 0 & 0 & 0 & 0 & 0 & 0 & 0 & 0 & 0 & 0 \\
\hline
\end{tabular}

Table 3. Products $v_{j i}^{\prime \prime}$ matrix for equation (18).

\begin{tabular}{cccccccccccccc}
\hline Reaction & Cell & ACell & Char & LVG & HAA & Glyoxal & Acetaldehyde & HMFU & Acetone & $\mathbf{C O}_{2}$ & $\mathbf{C O}$ & $\mathbf{H}_{2} \mathbf{O}$ & $\mathbf{C H}_{4}$ \\
\hline $\mathbf{1}$ & 0 & 1 & 0 & 0 & 0 & 0 & 0 & 0 & 0 & 0 & 0 & 0 & 0 \\
$\mathbf{2}$ & 0 & 0 & 6 & 0 & 0 & 0 & 0 & 0 & 0 & 0 & 0 & 5 & 0 \\
$\mathbf{3}$ & 0 & 0 & 0 & 1 & 0 & 0 & 0 & 0 & 0 & 0 & 0 & 0 & 0 \\
$\mathbf{4}$ & 0 & 0 & 0,61 & 0 & 0,95 & 0,25 & 0,2 & 0,25 & 0,2 & 0,16 & 0,23 & 0,9 & 0,1 \\
\hline
\end{tabular}

\subsubsection{Mass conservation equation for gas phase}

Whole mass conservation for the gas phase is not needed in this work because the mass conservation is a restriction in the equilibrium computations in CANTERA. Although, formally the mass conservation is presented in (20).

$$
\frac{\partial \rho_{g}}{\partial t}=\dot{S}^{\prime}
$$

Equation 20 do not account the exit of mass. Since an exit surface is not defined, is not possible to define an exit velocity, therefore, the exit mass is included in the source term, consequently 


$$
\dot{S}_{\text {devo }} \neq-\dot{S}^{\prime}
$$

where $\dot{S}^{\prime}$ is the mass source of the gas phase. The gas phase composition is computed using the mass species conservation

$$
\frac{\partial \rho_{i}^{\prime}}{\partial t}=\dot{S}_{i}^{\prime}
$$

Prime is added in the density of species $i$ because (22) is not the mass conservation of the whole gas phase. In (22) $\dot{S}_{i}^{\prime}$ is the source term related to the solid phase. Is worth to note that $\dot{S}_{i}^{\prime}$ is a density generation term, and it is related to the gas volume fraction $g$. Equation 22 is an intermediate step only for the purpose to determine the change in composition.

Species produced in solid phase are released in the gas phase, but the species produced not belong to this phase, and as proposed earlier this amount of mass must be transformed to an elemental basis. The amount of mass released from the solid phase is known through a set of equations of the form of (11). In order to transform the set of species released from the solid phase to elemental basis (23) is defined:

$$
\left[\mathrm{CHON}_{s}\right]\left\{\frac{d \rho_{B}^{\prime}}{d t}\right\}=\left\{\frac{d \rho_{E l}}{d t}\right\}
$$

In this equation $\mathrm{CHON}_{S}$ is a $p \times q$ matrix (Table 4) that contains the conversion factor needed to obtain the amount of mass of each elemental species released from the solid phase. In the $C H O N_{s}$ matrix $p$ is the number of elemental species considered, i.e. in this work carbon $\mathrm{C}$, hydrogen $\mathrm{H}$, oxygen $\mathrm{O}$ and nitrogen $\mathrm{N}$, and $q$ is the total number of specie released in the gas phase i.e. LVG, HAA, Glyoxal, Acetaldehyde, HMFU, Acetone, $\mathrm{H} 2 \mathrm{O}, \mathrm{CO} 2, \mathrm{CO}, \mathrm{H} 2 \mathrm{O}$ and $\mathrm{CH} 4$ (obtained from the reaction mechanism). On the other hand $\left\{\frac{d \rho_{B}}{d t}\right\}$ is the derivative of the species vector from solid phase and $\left\{\frac{d \rho_{E l}}{d t}\right\}$ is the resulting derivative of element vector, combining (12) and (23)

$$
\left\{\frac{d \rho_{E l}}{d t}\right\}=-\frac{s}{g}\left[\text { CHON }_{s}\right]\left\{\sum_{i=1}^{M} v_{j, i} \frac{M_{j}}{M_{i}} \frac{d \rho_{i}}{d t}\right\}
$$

Table 4. CHON matrix.

\begin{tabular}{ccccccccccc}
\hline & LVG & HAA & Glyoxal & Acetaldehyde & HMFU & Acetone & $\mathbf{C O}_{2}$ & $\mathbf{C O}$ & $\mathbf{H}_{2} \mathbf{O}$ & $\mathbf{C H}_{\mathbf{4}}$ \\
\hline $\mathbf{C}$ & 0,444 & 0,40 & 0,414 & 0,55 & 0,57 & 0,62 & 0,27 & 0,43 & 0,00 & 0,75 \\
$\mathbf{H}$ & 0,062 & 0,07 & 0,034 & 0,09 & 0,05 & 0,10 & 0,00 & 0,00 & 0,11 & 0,25 \\
$\mathbf{O}$ & 0,494 & 0,53 & 0,552 & 0,36 & 0,38 & 0,28 & 0,73 & 0,57 & 0,89 & 0,00 \\
$\mathbf{N}$ & 0,000 & 0,00 & 0,000 & 0,00 & 0,00 & 0,00 & 0,00 & 0,00 & 0,00 & 0,00 \\
\hline
\end{tabular}

Equation 24 include the factor $\frac{s}{g}$ to transform from the solid density basis to the gas density basis, where $s$ is the volumetric fraction of solid phases and $g$ the volumetric fraction of the gas phase.

It is worth to note that the variation of elements in the gas phase are expressed by the change of the cellulose and activated cellulose through the $\frac{d \rho_{i}}{d t}$. The final step is to compute the element mass fraction using (2)

$$
\frac{d \rho_{e l}^{\prime}}{d t}=\frac{d\left(\rho_{g}^{\prime} Y_{e l}\right)}{d t}
$$

In order to compute the mass fraction vector is necessary to calculate the term $\rho_{g}^{\prime}$. As aforementioned this gas density is not the equilibrium density, it is only the change in density do to the amount of gas released from the solid phase added to the actual gas density. In other words $\rho_{g}^{\prime}$ is an "unbalanced gas density". This term is computed using (22), (4) and (3) 


$$
\frac{\partial \rho_{g}^{\prime}}{\partial t}=-\frac{s}{g} \dot{S}_{\text {devo }}
$$

This equation express that the variation of solid density is equal to the unbalanced density variation of gas phase, considering the volumetric factor conversion.

In summary, in order to obtain a solution, 14 ordinary differential equations must be solved: 3 for solids species, cellulose (eq. 14), activated cellulose (15) and char (15); lequation for each gas released LVG, HAA, Glyoxal, Acetaldehyde, $\mathrm{HMFU}$, Acetone, $\mathrm{H}_{2} \mathrm{O}, \mathrm{CO}_{2}, \mathrm{CO}, \mathrm{H}_{2} \mathrm{O}$ (12) type, and 1 equation for the unbalanced density (27).

\subsection{Numerical solution}

The equation system is solved numerically with a simple as possible method at this starting stage, leaving a more complex solution scheme for future works. The most simple is the Euler method, however the latter has the disadvantage that can produce mass inconsistencies. Applying Euler to (15) yield the follow numeric scheme:

$$
\rho_{\text {Cell } n+1}=\rho_{\text {Cell } n}-\Delta t\left(k_{1}+k_{2}\right) \rho_{\text {Cell } n}
$$

In order to obtain consistent positive solutions (density cannot be less than zero) a restriction over the time step must be imposed.

$$
\Delta t<\frac{1}{\left|\left(k_{1}+k_{2}\right)\right|}
$$

Since $k_{1}$ and $k_{2}$ is always positive and can be significantly large, the time step must be prohibitively short. This constraint is avoided if Totally Implicit Euler method TIE (30) is applied. Applying TIE to cellulose yields:

$$
\rho_{\text {Cell } n+1}=\rho_{\text {Cell } n}-\left(k_{1}+k_{2}\right) \rho_{\text {Cell } n+1} \Delta t
$$

solving for $\rho_{\text {Cell } n+1}$

$$
\rho_{\text {Cell } n+1}=\frac{\rho_{\text {Cell } n}}{1+\left(k_{1}+k_{2}\right) \Delta t}
$$

Since all the terms in the right hand of equation 31 are positive, the scheme is consistent for any time step. The TIE is applied to all equations excepting equation (24). The later equation will be integrated later considering the reactor volume fraction.

Applying the TIE scheme to (14)-(16) gives the following set of algebraic equations.

$$
\begin{gathered}
\operatorname{Cell}_{n+1}=\frac{\operatorname{Cell}_{n}}{1+\left(k_{1}+k_{2}\right) \Delta t} \\
\operatorname{ACell}_{n+1}=\frac{\operatorname{ACell}_{n}+\Delta t \operatorname{Cell}_{n+1}}{\left(1+k_{3}+k_{4}\right) \Delta t} \\
\operatorname{Char}_{n+1}=\operatorname{Char}_{n}+\left(6 k_{2} \text { Cell }_{n+1}+0,61 k_{4} \text { ACell }_{n+1}\right) \Delta t
\end{gathered}
$$

For the species released in the gas phase a direct integration is computed for (24)

$$
\begin{aligned}
& \int\left\{\frac{d \rho_{E l}}{d t}\right\} d t \\
& =-\frac{s}{g}\left[\text { CHON }_{s}\right] \int\left\{\sum_{i=1}^{M} v_{j, i} \frac{M_{j}}{M_{i}} \frac{d \rho_{i}}{d t}\right\} d t
\end{aligned}
$$

Using the fundamental theorem of calculus 


$$
\left\{\rho_{E l, n+1}\right\}=-\frac{s}{g}\left[\mathrm{CHON}_{s}\right]\left\{\sum_{i=1}^{M} v_{j, i} \frac{M_{j}}{M_{i}} \Delta \rho_{i}\right\}
$$

Where integration constant is not considered because only the change in elemental concentration is needed. In (35) $\Delta \rho_{i}$ is the variation of cellulose and activated cellulose densities computed using (31) and (32).

Equation 27 is also directly integrated in time. Combining with equation 13

$$
\int \frac{\partial \rho_{g}^{\prime}}{\partial t} d t=-\frac{s}{g} \int \frac{\partial \rho_{s}}{\partial t} d t
$$

Using the fundamental theorem of calculus

$$
\rho_{g, n+1}^{\prime}=\rho_{g, n}-\frac{s}{g} \Delta \rho_{s}
$$

Where $\frac{s}{g}\left(\Delta \rho_{s}\right)$ is the sum of density variation (unbalanced) of all species in the gas phase that can be calculated from (31)-(33), and $\rho_{g, n}$ is the "balanced" density of the gas phase in time $t_{n}$, therefore the prime can be eliminated.

Equation 22 is integrated in vector form, and recognizing that (Turns)

$$
\rho_{i}^{\prime}=\rho_{g}^{\prime} Y_{g, i}
$$

then

$$
\left\{\int \frac{d \rho_{g}^{\prime} Y_{g, i}}{d t} d t\right\}=\left\{\int \quad \dot{S}_{i}^{\prime} d t\right\}
$$

solving

$$
\left\{\left(\rho_{g}^{\prime} Y_{g, i}\right)_{n+1}\right\}=\left\{\left(\rho_{g}^{\prime} Y_{g, i}\right)_{n}\right\}+\left\{\Delta S_{i}^{\prime}\right\}
$$

The last term in (40) is the mass variation vector (in volume basis) of the species considered in the gas phases, i.e. for this work $\mathrm{CO}_{2}, \mathrm{CO}, \mathrm{H}_{2} \mathrm{O}, \mathrm{CH}_{4}, \mathrm{H}_{2}$ and $\mathrm{N}_{2}$, and it must to be equal to the mass released from the solid phase in the interval $d t$. The first term of the right hand of (40) is the initial vector of species of the gas phase in $t_{n}$, so the prime can be eliminated. The term in the left hand is the new composition, the unbalanced species densities. Equation 40 can be written recognizing that densities are scalar quantities

$$
\rho_{g, n+1}^{\prime}\left\{Y_{g, i, n+1}\right\}=\rho_{g}\left\{Y_{g, i, n}\right\}+\left\{\Delta S_{i}^{\prime}\right\}
$$

The last term in the right hand of (41) is not possible to compute due to there is no reactions nor kinetics to transform the species released from the solid phase to the gas phase. However, (35) gives the change in the elemental composition obtained from the solid phase. Therefore, (41) must be transformed to elemental basis in order to compute with (35) in the same dimension.

The same procedure used for (23) is applied in (41), but the CHON matrix is different due to the species considered in the gas phase are different than species released from the solid phase. Therefore a new $\mathrm{CHON}$ matrix named $\mathrm{CHONg}$ is defined (See Table 5). Applying this procedure to equation 41

$$
\rho_{g, n+1}^{\prime}\left\{Y_{E l, g, i, n+1}\right\}=\operatorname{CHON}_{g}\left(\rho_{g}\left\{Y_{g, i, n}\right\}+\left\{\Delta S_{i}^{\prime}\right\}\right)
$$




\begin{tabular}{ccccccc}
\hline & $\mathbf{C O}_{2}$ & $\mathbf{C O}$ & $\mathbf{H}_{\mathbf{2}} \mathbf{O}$ & $\mathbf{C H}_{4}$ & $\mathbf{H}_{\mathbf{2}}$ & $\mathbf{N}_{\mathbf{2}}$ \\
\hline $\mathbf{C}$ & 0,273 & 0,429 & 0,000 & 0,750 & 0,000 & 0,000 \\
$\mathbf{H}$ & 0,000 & 0,000 & 0,111 & 0,250 & 1,000 & 0,000 \\
$\mathbf{O}$ & 0,727 & 0,571 & 0,889 & 0,000 & 0,000 & 0,000 \\
$\mathbf{N}$ & 0,000 & 0,000 & 0,000 & 0,000 & 0,000 & 1,000 \\
\hline
\end{tabular}

Now the vector term in the left hand is the unbalanced elemental vector of the gas phase. Distributing CHONg and recognizing that

$$
\operatorname{CHON}_{g}\left\{\Delta S_{i}^{\prime}\right\}=\left\{\rho_{E l, n+1}\right\}
$$

then

$$
\rho_{g, n+1}^{\prime}\left\{Y_{E l, g, i, n+1}\right\}=\operatorname{CHON}_{g} \rho_{g}\left\{Y_{g, i, n}\right\}+\left\{\rho_{E l, n+1}\right\}
$$

and the final equation for the new elemental mass fraction of the gas phase due to the gas released through devolatilization process is

$$
\left\{Y_{E l, g, i, n+1}\right\}=\frac{\text { HHON }_{g} \rho_{g}\left\{Y_{g, i, n}\right\}+\left\{\rho_{E l, n+1}\right\}}{\rho_{g, n+1}^{\prime}}
$$

In words, (45) express that the mass fraction vector of the gas phase in time $t_{n}$ is converted to elemental basis, and is added to the species released from the solid phase, also, in elemental basis. Dividing by the unbalanced density yields the new mass fraction for the gas phase due to the devolatilization process.

The vector on the left hand of (45), in conjunction with the pressure, and the current temperature are the inputs for CANTERA to compute the equilibrium composition.

It is worth to note that the unbalanced term will disappear because the equilibrium calculation will generate a new gas density according to the new elemental vector, pressure and current temperature. It means that there is a relaxation process in which after the gas was released from the solid phase, the increased pressure cause the exit of mass until the constant pressure is reached again. This process is infinitely fast, therefore at the process time scale (macro scale) the pressure is captured such as constant. The new composition is expressed in terms of the gas phase species i.e. $\mathrm{CO}_{2}, \mathrm{CO}, \mathrm{H}_{2} \mathrm{O}$, $\mathrm{CH}_{4}, \mathrm{H}_{2}$ and $\mathrm{N}_{2}$.

\subsection{Algorithm}

In order to determine the new equilibrium composition all the equations of the system must be solved simultaneously. However, since the structure of the system it is possible to solve in a sequence way. Fig. 4 shows a diagram for the solving procedure. 


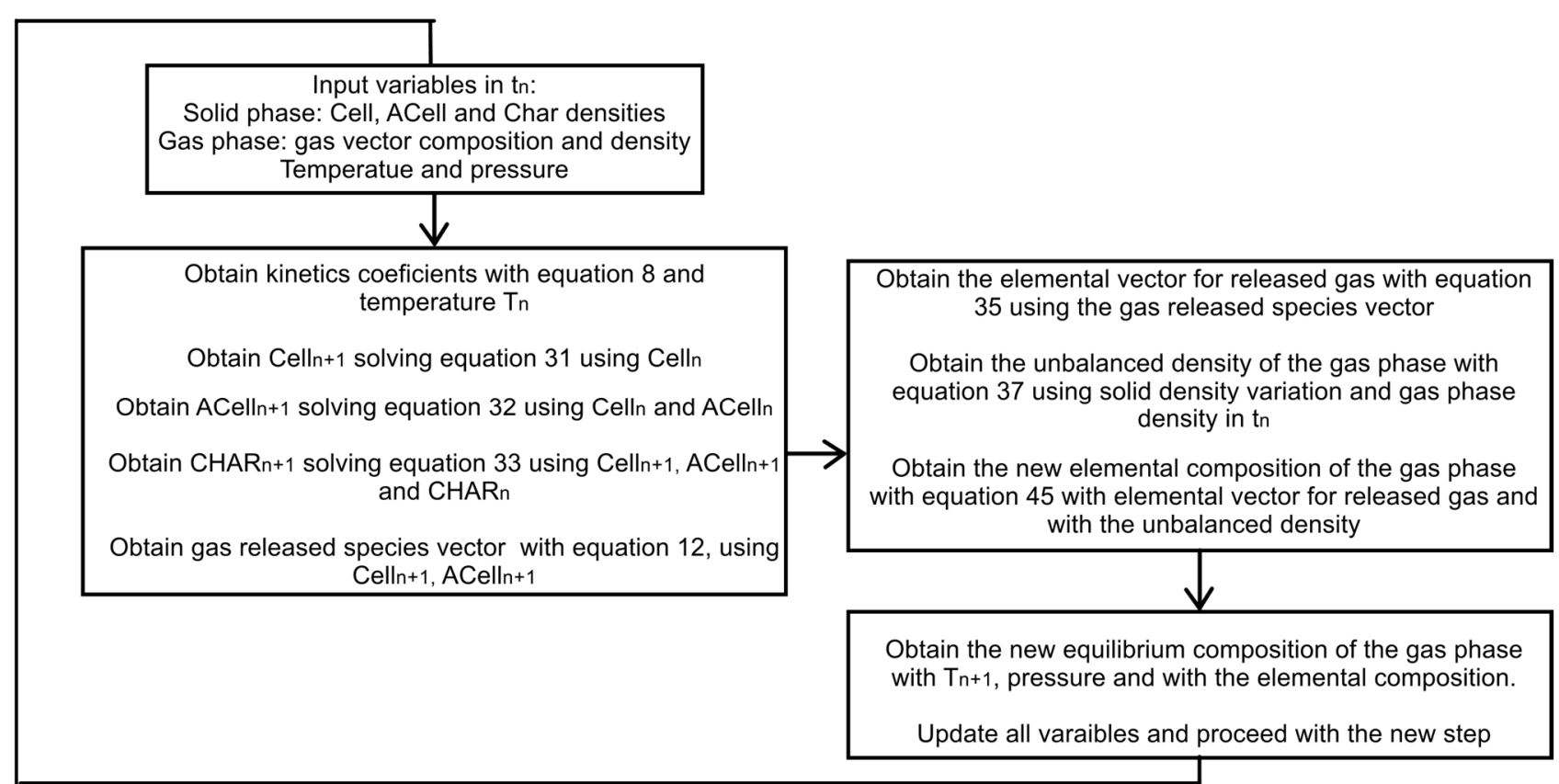

Fig. 4. Algorithm.

\section{Results and discussion}

The results for the model proposed in above sections are presented here. The simulations was performed with a linear temperature profile. In a actual reactor environment the temperature profile depends on transport properties. For example for a fixed bed batch reactor, where biomass is in a steel box opened on the top side, heat can be supplied from electrical heaters, directly on the top side by radiation, and trough the steel walls through conduction. Biomass temperature can be controlled linearly at the top and near the walls. However, probably inner points in the bed do not experiments a linear heat up, due to the transport resistances. This model do not account transport terms so all biomass is heated up at the same regime.

Required properties for cellulose, activated cellulose, char and gaseous species are tabulated in Table 6 and Table 7. For all simulation molecular nitrogen is considered the only species in the gas phase at $\mathrm{t}=0$, due to it is a common condition in order to avoid combustion. Initial conditions and parameters are presented in Table 8.

Table 6. Solid physical properties [12].

\begin{tabular}{lcc}
\hline & Density $\left[\mathbf{k g} / \mathbf{m}^{\mathbf{3}}\right]$ & Molar Mass $[\mathbf{k g} / \mathbf{k m o l}]$ \\
\hline Cellulose & 400 & 162 \\
\hline Activated Cellulos & 400 & 162 \\
\hline Char (C graphite) & 2333 & 12 \\
\hline
\end{tabular}

Table 7. Molecular formula and molar mass [12].

\begin{tabular}{ccccccccccc}
\hline & LVG & HAA & Glyoxal & Acetaldheyde & HMFU & Acetone & $\mathbf{C O}_{2}$ & $\mathbf{C O}$ & $\mathbf{H}_{2} \mathrm{O}$ & $\mathbf{C H}_{4}$ \\
\hline $\begin{array}{c}\text { Formula } \\
\text { Molar mass } \\
{[\mathbf{k g} / \mathbf{k m o l}]}\end{array}$ & $\mathrm{C}_{6} \mathrm{H}_{10} \mathrm{O}_{5}$ & $\mathrm{C}_{2} \mathrm{H}_{4} \mathrm{O}_{2}$ & $\mathrm{C}_{2} \mathrm{H}_{2} \mathrm{O}_{2}$ & $\mathrm{C}_{3} \mathrm{HCO}$ & $\mathrm{C}_{6} \mathrm{H}_{6} \mathrm{O}_{3}$ & $\mathrm{C}_{3} \mathrm{H}_{6} \mathrm{O}$ & - & - & - & - \\
\hline
\end{tabular}

Fig. 5 shows the evolution of the solid phase with a heating rate of $18 \mathrm{~K} / \mathrm{min}$. The gas density in this figure is the amount of gas released relative to the solid density basis. The devolatilization process start around $453 \mathrm{~K}$ (i.e. around $550 \mathrm{~s}$ ). The species produced are mainly $\mathrm{H}_{2} \mathrm{O}$ and char through the (R2), directly from virgin cellulose. 
Gas released from solid phase is practically only $\mathrm{H}_{2} \mathrm{O}$ (near at $700 \mathrm{~s}$ ), and as can be observed in Fig. 6 , gas phase is composed only by $\mathrm{H}_{2} \mathrm{O}$ and $\mathrm{N}_{2}$. LVG and other gases produced by (R4), are practically not released, due to activated cellulose will start to produce only i.e after $700 \mathrm{~s}$ (Fig. 5), therefore char is produced before other gases. The quantity of gas and char produced in this first stage is relatively low, due to the mass fraction of virgin cellulose is practically 1 (Fig. 5). $\mathrm{H}_{2} \mathrm{O}$ present in the gas phase is mainly produced by dehydration of virgin cellulose through (R2). When activated cellulose is produced, an increase of $\mathrm{CO}_{2}$ mass fraction is observed in the gas phase (Fig. 6), it is means that some LGV, HAA, Glyoxal, Acetaldehyde, $\mathrm{HMFU}, \mathrm{CO}_{2}, \mathrm{CO}, \mathrm{H}_{2} \mathrm{O}, \mathrm{CH}_{4}$ species are produced by (R3) and (R4). The latter reaction produce some water too, so, part of the water present in the gas phase is due the contribution of (R3) and (R4). This release is not direct due to the gas phase is considered in chemical equilibrium, however, due to the system temperature, i.e. $570 \mathrm{~K}, \mathrm{H}_{2} \mathrm{O}$ and $\mathrm{CO}_{2}$ is favored by chemical equilibrium.

When activated cellulose is produced, the gas density is start to increase rapidly (Fig. 5). This is the main weight loss along the process, but due to the inertia effect caused by the kinetics (introduced by the addition of the activated cellulose [21]), gas density is started to rise after the cellulose consumption.

Starting from $550 \mathrm{~K}$, i.e. near $900 \mathrm{~s}$, competitive char-gas reactions favor the gas yield (Fig. 5), according with Di Blasi [3]. The pyrolysis process is finished slightly after that the system temperature was constant at $673 \mathrm{~K}$, when cellulose was completely depleted. This behavior is in agreement as described in the literature that states the cellulose decompose over a range from 598 to $648 \mathrm{~K}$ [3], and as can be observed here, the main devolatilization process take place near this range.

Table 8. Initial conditions and process parameters.

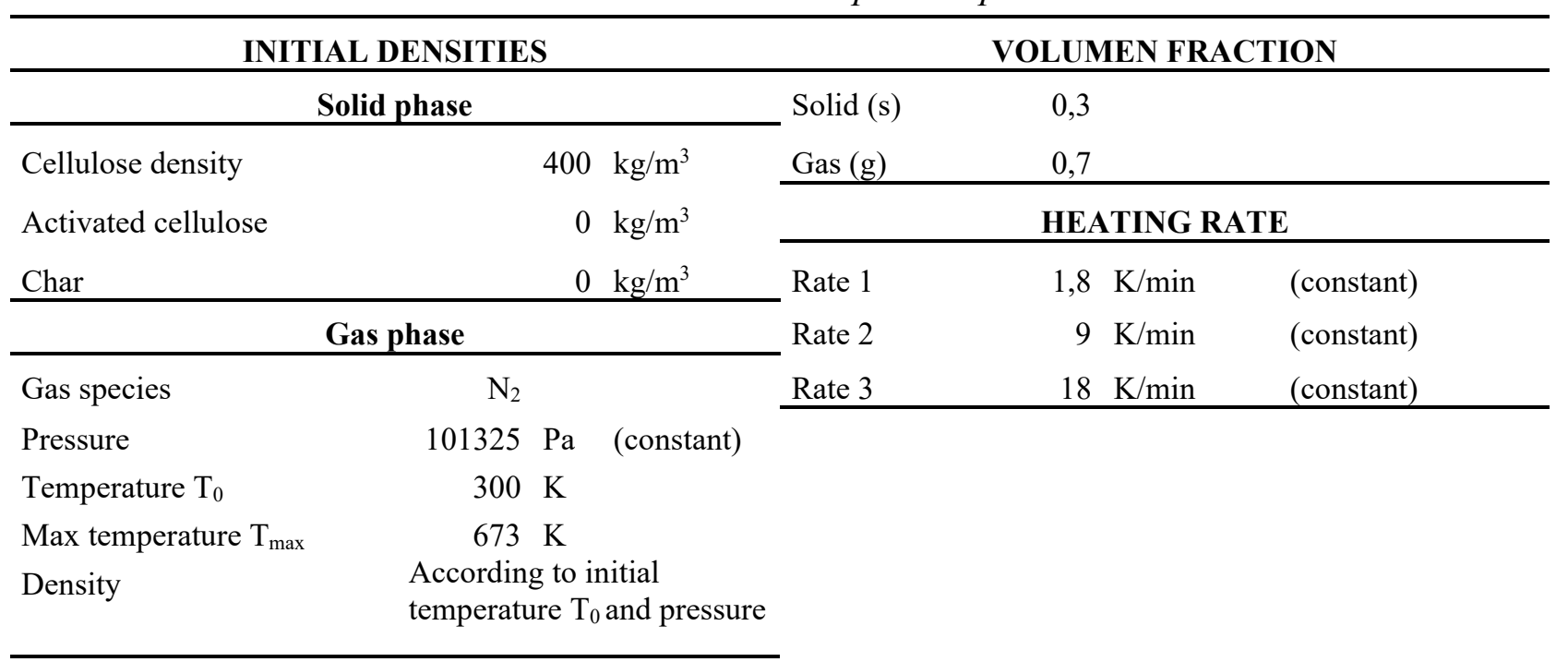




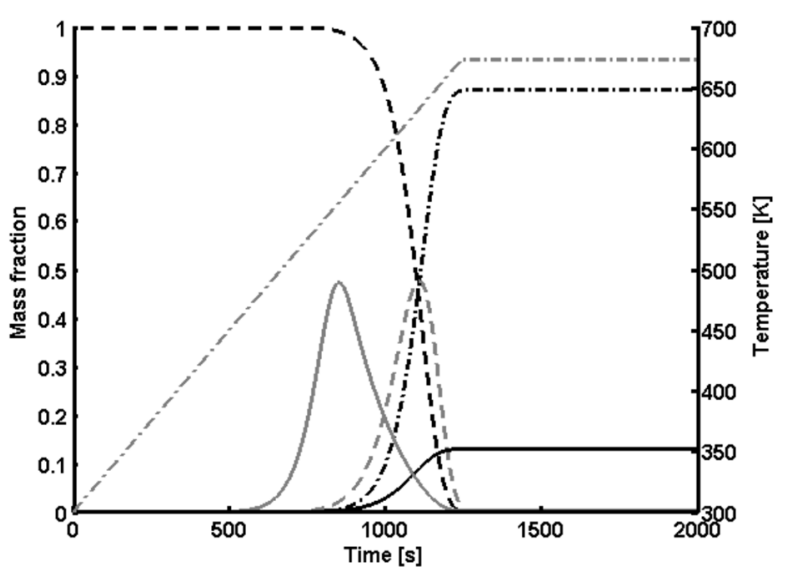

Fig. 5. Parameters Heating rate $=18[\mathrm{~K} / \mathrm{min}] \mathrm{T0}$ $=300 \quad[K] \quad$ Tmax $=673 \quad[K]$. Gray: (-.-) Temperature,(--) ACell x 100, (-) $\mathrm{H}_{2} \mathrm{O}$. Black: (-) Cell, (-.-) Gas density, (-) Char.

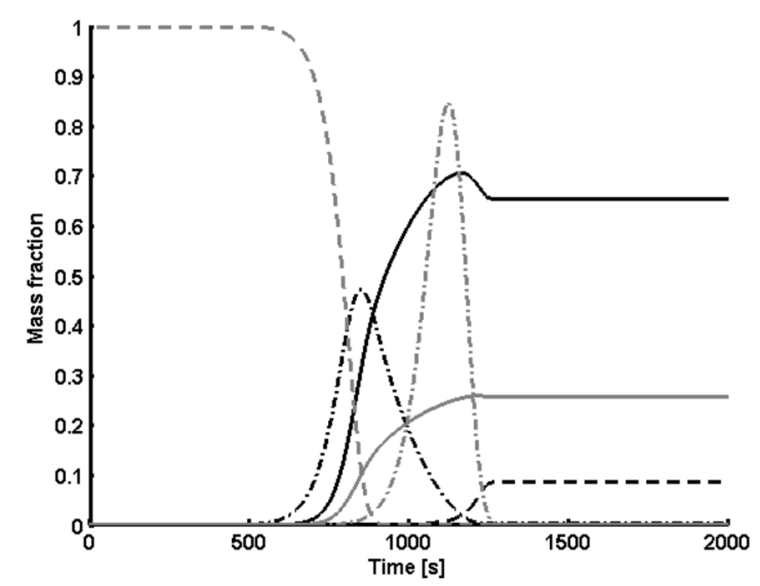

Fig. 6. Parameters Heating rate $=18[\mathrm{~K} / \mathrm{min}]$ T0 $=300[$ K] Tmax $=673$ [K]. Gray: (-.-) Elemental carbon from solid phase, (--) $\mathrm{N}_{2}$, (-) $\mathrm{CH}_{4}$. Black: (--) $\mathrm{CO},(-.-) \mathrm{H}_{2} \mathrm{O}$, (-) $\mathrm{CO}_{2}$.

The final mass fraction of carbon is $13 \%$ and gas is $87 \%$. The carbon mass fraction is higher than reported in literature [3] that state the char from cellulose is around 5\% in mass basis. This behavior is due that the total carbon produced by (R2) and (R4) is assigned to the solid phase and no solid carbon is present in the gas phase. Char particles produced by (R2) and (R4) is considered, in this work, belong exclusively to the solid matrix, and no conversion after is considered (no secondary cracking reactions), therefore, the result is a very clean gas.

In actual pyrolysis processes the gas is not clean, and an additional process is needed to separate char from gases [1], [4]. On the other hand, the temperature is low, between 300 and $673 \mathrm{~K}$, and the heating rate is relatively slow, $18 \mathrm{~K} / \mathrm{min}$, this condition favored the char yield. Lower yields of char is obtained with high heating rates and higher temperatures [1], [3] and [4].

The gas phase in this work is considered in chemical equilibrium permanently, at a one atmosphere, and with a variable temperature. Species produced from solid phase, except char and activated cellulose, is equilibrated in the zero dimensional gas system, at the reactor constant pressure and current temperature conditions. In the earlier stage the only species present in the gas phase is $\mathrm{N}_{2}$ (Fig. 6). As showed in the Fig. 7, $\mathrm{N}_{2}$ density decrease as the temperature increases at constant pressure and volume. $\mathrm{N}_{2}$ density evolution has two stage. First stage is caused only due to the higher temperature and then the density is lowered (in order to maintain a constant pressure), this effect cause a flow out of pure nitrogen. Later, when practically solely $\mathrm{H}_{2} \mathrm{O}$ is released in the gas phase, the $\mathrm{N}_{2}$ density decrease more rapidly due to the higher temperature and due to the higher $\mathrm{H}_{2} \mathrm{O}$ content.

The $\mathrm{CO}_{2}$ in the gas phase is started to rise after the $\mathrm{H}_{2} \mathrm{O}$ species, as can be seen in the Fig. 6. In Fig. 8, conveniently scaled, are shown: elemental carbon, oxygen, hydrogen and activated cellulose relative to the solid phase density. There is clearly correlation between the elemental species and activated cellulose.

The main elemental species produced is oxygen, and this species is the element with higher mass fraction in the $\mathrm{CO}_{2}$ molecule (i.e. $28 \% \mathrm{C}$ and $72 \% \mathrm{O}$ ), and even though the elemental carbon released is low, (between 600 and $800 \mathrm{~s}$, see Fig. 8) the $\mathrm{CO}_{2}$ mass fraction is higher due to the oxygen content (see Fig. 6). 


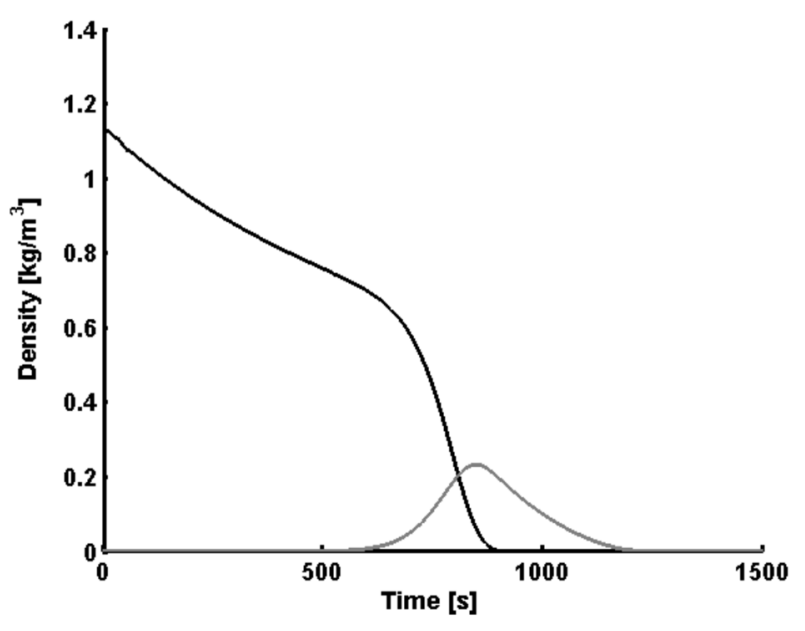

Fig. 7. Parameters Heating rate $=18[\mathrm{~K} / \mathrm{min}] \mathrm{TO}$ $=300[\mathrm{~K}]$ Tmax $=673$ [K]. Gray: (-) $\mathrm{H}_{2} \mathrm{O}$, (--). Black:(-) $N_{2}$.

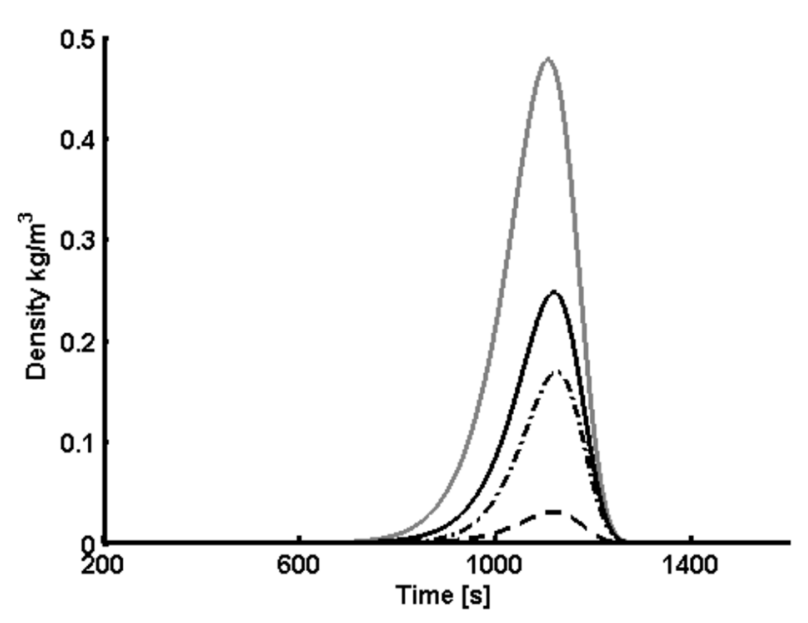

Fig. 8. Parameters Heating rate $=18[\mathrm{~K} / \mathrm{min}] \mathrm{T0}$ $=300[$ K] Tmax $=673$ [K]. Gray: (-) ACell x 100. Black:(-) O/10, (-.-) C/10, (--) H/10, elemental species produced from the solid phase.

The devolatilization is practically finished at $1250 \mathrm{~s}$, when temperature is $673 \mathrm{~K}$ and constant. At this stage the $\mathrm{CO}$ is significatively high, but only due to the chemical equilibrium (Fig. 6). It is also possible to observe in Fig. 6 that $\mathrm{CO}$ yield increases at expense of $\mathrm{CO}_{2}$ gas, instead the $\mathrm{CH}_{4}$.

At this stage the species $\mathrm{CO}$ and $\mathrm{CH}_{4}$ contributes to the $\mathrm{HV}$. Gas phase composition before $1250 \mathrm{~s}$, is not important because there is a remainder gas inside the reactor. Therefore, if the temperature in the reactor changes the composition will change due to the chemical equilibrium instead devolatilization, because no more gas is produced.

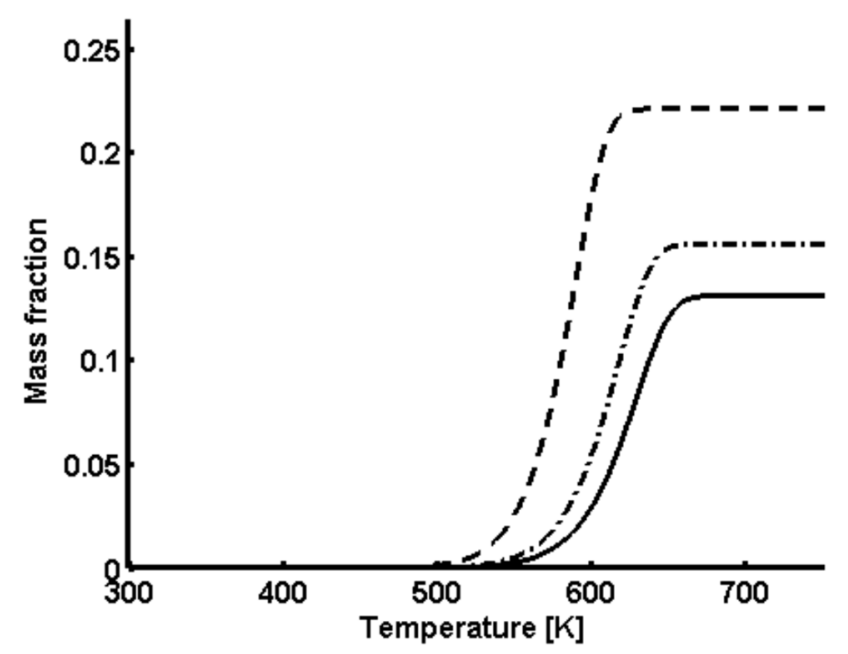

Fig. 9. Char yield at three heating rates. (--) 1,8 $\mathrm{K} / \mathrm{min}$, (-.-) $9,0 \mathrm{~K} / \mathrm{min}$. (-) $18,0 \mathrm{~K} / \mathrm{min}$.

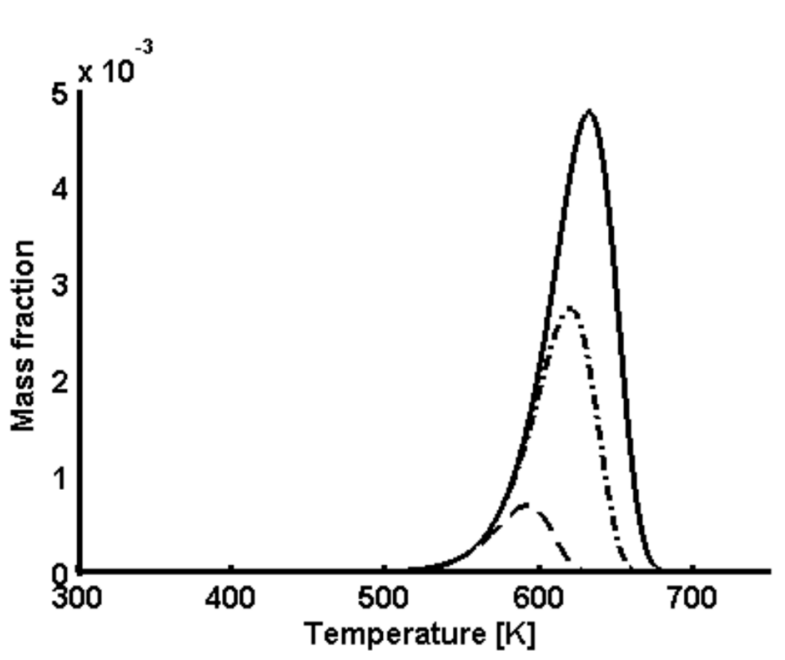

Fig. 10. Acell yield at three heating rates. (--) 1,8 $\mathrm{K} / \mathrm{min}$, (-.-) $9,0 \mathrm{~K} / \mathrm{min}$, (-) $18 \mathrm{~K} / \mathrm{min}$.

Fig. 9 shows the effect of the competitive characteristic of cellulose pyrolysis as mentioned in literature [3]. For lower rate i.e. $1,8 \mathrm{~K} / \mathrm{min}$ the char yield is higher than the yield at 9,0 and 18,0 $\mathrm{K} / \mathrm{min}$. This is due that the solid phase remains more time at lower temperature, which favored the char and dehydration reactions. Considering that the lower heating rate of $1,8 \mathrm{~K} / \mathrm{min}$, is 5 times lower than the $9,0 \mathrm{~K} / \mathrm{min}$ heating rate, and $18,0 \mathrm{~K} / \mathrm{min}$ is only 2 times higher than $9 \mathrm{~K} / \mathrm{min}$, as can be seen in Fig. 9, the change in the char yield from 1,8 to $9,0 \mathrm{~K} / \mathrm{min}$ is higher than the change in yield of char form 9,0 to $18,0 \mathrm{~K} / \mathrm{min}$. This effect is because the exponential characteristic of the rate equations. 
Fig. 10 shows a higher peak concentration of the activated cellulose as the heating rate is increased. This behavior can explain the increase of the amount of gas released from the solid phase as the heating rate is increased. The rate equation (7) is composed by the kinetic and mass action law parts [20]. Therefore in one hand, the higher temperature caused by the fast heating rate favors the gas yield via the kinetic part, and on the other hand, the higher concentration of activated cellulose produce a higher gas yield due the mass action law.

Other characteristic that is possible to observe in Fig. 10, is that the activated cellulose production starts always, nearly at the same temperature, however the temperature range in which the activated concentration is significatively high, is wider as the heating rate is higher. The contrary effect is seen if the mass fraction of activated cellulose is plotted against the time (Fig. 11). As can be seen in the latter figure, as the heating rate is increased the period of time in which the activated cellulose is significatively high is narrower. This effect is due to that as the temperature is higher, the consumption of activated cellulose to produce the species through equations 3 and 4 is higher too, and therefore the concentration of activated cellulose is reduced more faster than at lower heating rate.

Finally, Fig. 12 shows the expected behavior, maintaining a variable extent of the devolatilization process [3], provided by the use of an competitive reaction mechanism [12]. The latter implies that the higher heating rate the shorter the devolatilization time. As the heating rate is increased the weight loss is increased in severity producing more gases and less char. This effect is due the competitive characteristic of the mechanism (Table 1). As can be observed in Table 1 the activation energy of (R3) is very low, therefore the reaction is very fast, however it is depend on the concentration of activated cellulose. Reaction for activated cellulose has an activation energy higher than (R1), therefore is a bottleneck, and only at high temperature can compete with (R1) to produce higher amounts of LVG.

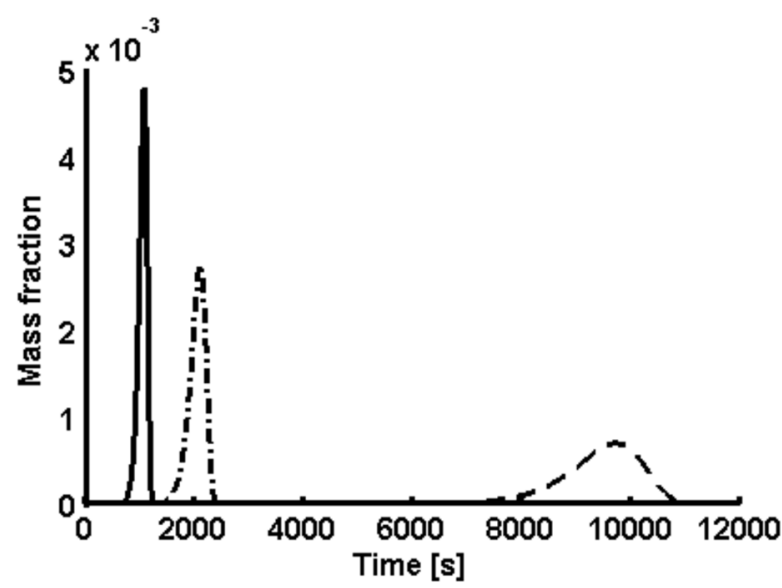

Fig. 11. ACell evolution at three heating rates. (--) $1,8 \mathrm{~K} / \mathrm{min},(-.-) 9,0 \mathrm{~K} / \mathrm{min}$, (-) $18 \mathrm{~K} / \mathrm{min}$.

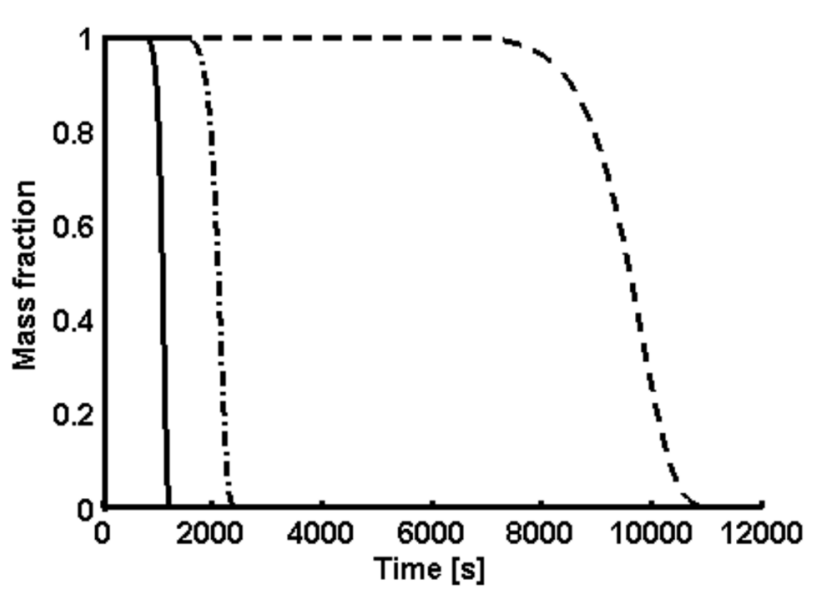

Fig. 12. Cell reduction at three heating rates. (--) $1,8 \mathrm{~K} / \mathrm{min},(-.-) 9,0 \mathrm{~K} / \mathrm{min}$, (-) $18 \mathrm{~K} / \mathrm{min}$.

\section{Conclusions}

As stated in objectives in the introductory part of this article the main goal of this work was to obtain in a simple description of the thermal degradation behavior of the cellulose pyrolysis, with focus on the char evolution and yield.

From the revision of the literature it was possible to observe that the most simple approach to study the pyrolysis process is the equilibrium approach, but its mainly applied to the gasification process. Further, the most important parameter of this work, the char yield, cannot be obtained from the pure equilibrium models. From the point of view of the char evolution characteristics, the approach proposed in this work, using a parallel semi-global reaction mechanism, provides the desired results similarly those obtained by other authors. 
The model solution is consistent and the set of ordinary differential equation was solved with a minimum complexity using the Totally Euler Implicit scheme. The procedure to predict the gas phase composition avoiding the kinetics and a set of homogeneous reactions, is a significant complexity reduction. Also the algorithm solution not contain any iterative loop (with the exception the internal loop in CANTERA) that always demand more computing capabilities, time and resources. The gas phase prediction is similarly to the gas compositions observed in the literature, showing that $\mathrm{CO}_{2}$, $\mathrm{H}_{2} \mathrm{O}$ and $\mathrm{CH}_{4}$ is mainly produced at low temperature process and $\mathrm{CO}$ at higher temperatures. $\mathrm{H}_{2}$ in this works practically has no presence due to the low temperature.

The complexity reduction was enhanced with the use of the free distributable software package CANTERA that compute the more difficult task, the chemical equilibrium.

The aspects analyzed in the final part of this article shows that the model can maintain the expected behavior for dynamical pyrolysis compared with the results showed by other authors (for rate of formation and yield of char). Specially the competitive factor between the gas released and char conversion as a function of the heating rate and maximum temperature is conserved. Further, the model include the time parameter, a factor that is not common, by definition in equilibrium computations.

In order to obtain a complete thermal behavior of biomass, the extension, using the superimposed hypothesis [8], is rather simple, considering that the structure of the semi-global reaction mechanisms for hemicellulose and lignin is similar to the scheme used for cellulose.

The disadvantages of the model are that is not possible to predict intermediate gases due to the lack of kinetics for the gas phase. Also secondary cracking reaction of vapor species like LVG, HAA, HMFU, Acetone, Acetaldhyde or Glyoxan is not accounted due to these species not belong to any phase defined in this work.

The next stage of this work is to include the space in the model to account the transport processes: advection, conduction and radiation. This initial work provide the necessary chemical framework in order to asses a reactor and the influences on the char conversion.

The procedure to adapt an existing reaction mechanism (dynamical approach) obtained from the literature is straightforward, also is possible to add this procedure with a short piece of code in a computational algorithm. Therefore, in order to evaluate a pyrolysis process in a reactor environment, in a short time and without the complexities of the fully dynamical description, is possible to start from the TG analysis or other reaction mechanism and obtain a good estimate of the pyrolysis behaviour.

\section{Acknowledgments}

Acknowledgements for the DIUFRO project DI12-0057 "Estudio Técnico-Económico para la optimización de la producción de pellets combustibles de desechos biomásicos forestales y agrícolas, y utilización de glicerol como agente densificador energético y plastificante.".

\section{Nomenclature}

\section{Symbols}




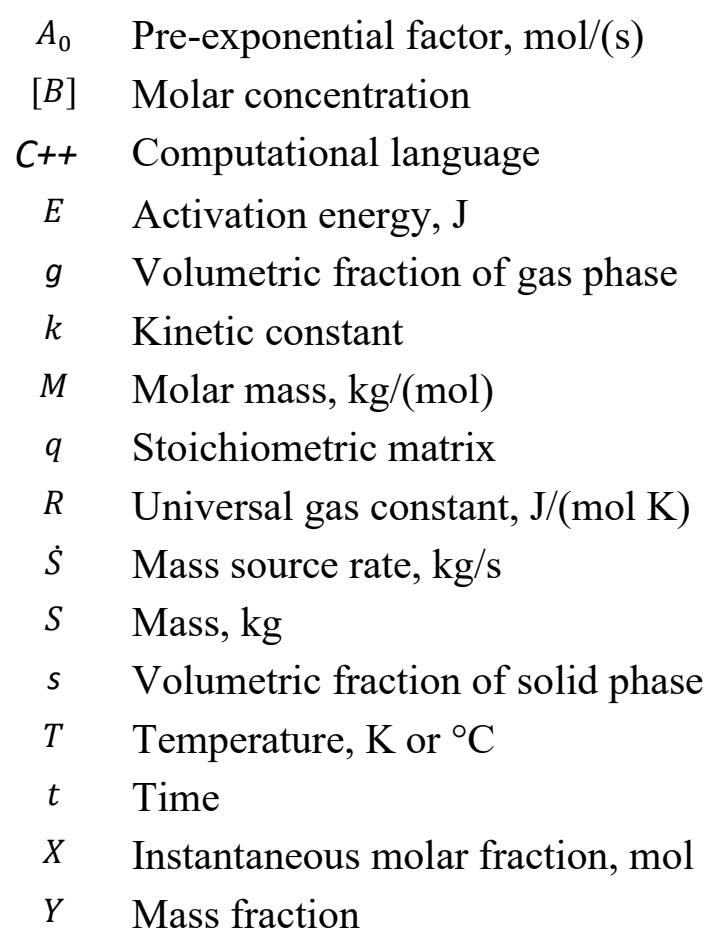

\section{Greek letters}

$v$ Stoichiometric coefficient

$\rho$ Density, $\mathrm{kg} / \mathrm{m}^{3}$

$\dot{\omega} \quad$ Molar mass rate, $\mathrm{mol} /(\mathrm{s})$

\section{Subscripts}

1,2,3, Reaction number of mechanism 4

ACell Activated cellulose

$B \quad B$ species $B$ in a reaction

$b \quad$ Backward reaction

Cell Cellulose

Char Char or Charcoal

Devo Devolatilization

El Element species

$f \quad$ Forward reaction

$g \quad$ Gaseous phase

i Species number

j Species number

$n \quad$ Current time step

$n+1 \quad$ Next time step

$s \quad$ Solid phase

\section{Superscripts}


(Prime) Denote Unbalanced quantity
$n \quad$ Temperature power for Arrhenius equation

\section{References}


[1] P. Basu, "Biomass Gasification and Pyrolysis and Torrefaction", Elsevier Inc, 3th edition, 2013.

[2] C. Wurzenberger, "A Combined Packed Bed and Single Particle Model Applied to Biomass Combustion". Dissertation Thesis, Technische Universitat Graz, 2001.

[3] C. Di Blasi, "Modeling chemical and physical processes of wood and biomass pyrolysis". Progress in Energy and Combustion Science, 34, 47-90 2008, doi:10.1016/j.pecs.2006.12.001

[4] A.V. Bridgwater, D. G. B. Boocock, "Developments in thermochemical biomass conversion", Springer Science + Business Media, volume I, Dordrecht, Netherlands, ISBN: 978-94-010-7196-3 (Print) 978-94-009-1559-6 (Online), 1997.

[5] S.C. Moldoveanu, "Analytical Pyrolysis of Natural Organic Polymers", Elsevier Science, 1st Edition, ebook ISBN: 9780080527161, 1998.

[6] J.P. Diebold, A.V. Bridgwater, "Overview of fast pyrolysis of biomass for the production of liquid fuels" Developments in Thermochemical biomass conversion, pp 5-23, 1997.

[7] M. Demirbas M, "Use of algae as biofuel sources" Energy Conversion and Management, volume 51, issue 12, pp 2738-2749, December 2010.

[8] R.S. Miller, J.A. Bellan, "Generalized Biomass Pyrolysis Model Based on Superimposed Cellulose, Hemiellulose and Lingnin Kinetics", Combustion Science and Technology, Volume 126, Issue 1-6, February 1997, DOI: 10.1080/00102209708935670.

[9] C. Branca, C. Di Blasi, "Kinetics of the isothermal degradation of wood in the temperature range 528-708 K", Journal of Analytical and Applied Pyrolysis, Volume 67, Issue 2, pp 207-219, May 2003.

[10] D.F. Arseneau, "Competitive Reactions in the Thermal Decomposition of Cellulose", Canadian Journal of Chemistry, volume 49, issue 4, pp 632-368, September 1971, DOI: $10.1139 / \mathrm{v} 71-101$.

[11] I.I. Ahmed, A.K. Gupta, "Sugarcane bagasse gasification: Global reaction mechanism of syngas evolution", Applied Energy, Volume 91, Issue 1, pp 75-81, March 2012, doi:10.1016/j.apenergy.2011.07.001.

[12] E. Ranzi, A.Cuoci, T. Faravelli, A. Frassoldati, G. Migliavacca, S. Pierucci and S. Sommariva, "Chemical Kinetics of Biomass Pyrolysis", Energy Fuels, volume 22, issue 6, pp 4292-4300, 2008, DOI: 10.1021/ef800551t.

[13] M.W. Zemansky "Heat and Thermodynamics" McGraw-Hill Companies; 7th edition, USA, ISBN 0-07-017059-2, 1997.

[14] S.R. Turns, "An introduction to combustion concepts and applications" McGraw Hill, 2th Edition, , Singapore, ISBN: 0-07-116910-5, 2000.

[15] P. Vonka, L. Jimdrich, "Calculation of chemical equilibrium in complex system: system restriction", Collect. Czech. Chem. Commun. Vol. 65, 2000.

[16] D.H. Lee, H. Yang, R. Yan, D.T, Liang, "Prediction of gaseous products from biomass pyrolysis through combined kinetic and thermodynamic simulations" volume 86 , issue 3, pp 410-417, February 2007, doi:10.1016/j.fuel.2006.07.020.

[17] C.R. Altafini, P.R. Wander, R.M. Barret, "Prediction of the working parameters of a wood waste gasifier through an equilibrium model", Energy Conversion and Management volume 44, issue 17, pp 2763-2777, October 2003, doi:10.1016/S01968904(03)00025-6. 
[18] M. Baratieri, P. Baggio, L. Fiori, M. Grigiante, "Biomass as an energy source: Thermodynamic constraints on the performance of the conversion process", Bioresource Technology, volume 99, issue 15, pp 7063-7073 October 2008, doi:10.1016/j.biortech.2008.01.006.

[19] B. Gøbel, U. Henriksen, T. Jensen, B. Qvale, P. Houbak, "The development of a computer model for a fixed bed gasifier and its use for optimization and control", Bioresource Technology volume 98, issue 10, Pages 2043-2052, July 2007, doi:10.1016/j.biortech.2006.08.019.

[20] M.E. Davis, R.J. Davis, "Fundamentals of chemical reaction engineering", McGraw Hill, 1st edition, New York, USA, ISBN 0-07-119260-3, 2003.

[21] Bradbury, A. G., Sakai, Y., Shafizadeh, F. A kinetic model for pyrolysis of cellulose. Journal of Applied Polymer Science, 23(11), 3271-3280, 1979).

[22] Cengel, Y. Termodinamica. McGraw-Hill Companies 2005.

[23] Jakobsen, H. A. Chemical reactor modeling. Multiphase Reactive Flows, Berlin, Germany: Springer-Verlag 2008. 